\title{
A parametric study of fault mechanical changes associated with geological
} sequestration of carbon dioxide

$\mathrm{CO}_{2}$ 地中貯留における断層の力学安定性に関するパラメータによる研究

\author{
Qi LI* and Zhishen WU ** \\ 李 琦・呉 智深 \\ * Dr. of Eng., Institute of Geology and Geoinformation, \\ National Institute of Advanced Industrial Science and Technology (AIST), \\ AIST Central 7, 1-1-1 Higashi, Tsukuba, Ibaraki, 305-8567, Japan \\ ** Dr. of Eng., Professor, Dept. of Urban \& Civil Engineering, Ibaraki University, \\ 4-12-1 Nakanarusawa-cho, Hitachi, Ibaraki 316-8511, Japan
}

In this paper, a geomechanical model is proposed to study the influence of $\mathrm{CO}_{2}$ (carbon dioxide) geological sequestration on the mechanical changes of faults around the injection well by the finite element simulation. Through the numerical parametric studies, such as the thickness and spread width of $\mathrm{CO}_{2}$ plume, the injection pressure, the depth of injection well and the caprock permeability, effects of the injection pressure and the buoyancy of $\mathrm{CO}_{2}$ plume on the mechanical changes of faults are clearly interpreted. The study shows that the shear stress change along the fault surface is sensitive to the variation of the injection pressure, the thickness and spread width of $\mathrm{CO}_{2}$ plume. The relative slip displacement of fault surfaces is significantly small in current studies. Finally, some suggesting remarks are concluded to decide ideal geological disposal sites for $\mathrm{CO}_{2}$ sequestration.

Key Words: fault, geological sequestration, mechanical changes, $\mathrm{CO}_{2}$

\section{Introduction}

With the humankind entering the 21 st century, natural hazards caused by the atmospheric greenhouse effect are becoming much more and more serious than ever before, and such a greenhouse effect is widely considered to be mainly caused by $\mathrm{CO}_{2}$ emission into the atmosphere from coal-fired power plants. To combat with this trend, major developed countries offered many proposals and launched a broad union in the world. In 1990s, governments signed many $R \& D$ projects with institutes, universities and consortiums to research the best choices to capture and disposal $\mathrm{CO}_{2}$. Up to now, the geological sequestration of captured $\mathrm{CO}_{2}$ into deep depleted reservoirs or saline aquifers is widely regarded as a promising option for large amount and long term disposal of $\left.\mathrm{CO}_{2}{ }^{2,}, 4,5,6,15\right)$ Until the fall of 2000, Japan government launched a five-year national $R \& D$ program of "Underground Storage of Carbon Dioxide" under the auspices of New Energy and Industrial Technology Development Organization (NEDO). In the 2002, Japanese Ministry of Economy, Trade and Industry (METI) began a five-year project on $\mathrm{CO}_{2}$ geological sequestration in coal seams. ${ }^{7,8)}$ In 2003, a small-scale field test of liquid $\mathrm{CO}_{2}$ injection has been started at the Iwanohara Base of the Teikoku Oil Co. Ltd in Nagaoka city, Niigata prefecture, conducted by Research Institute of Innovative Technology for the Earth (RITE) in close 


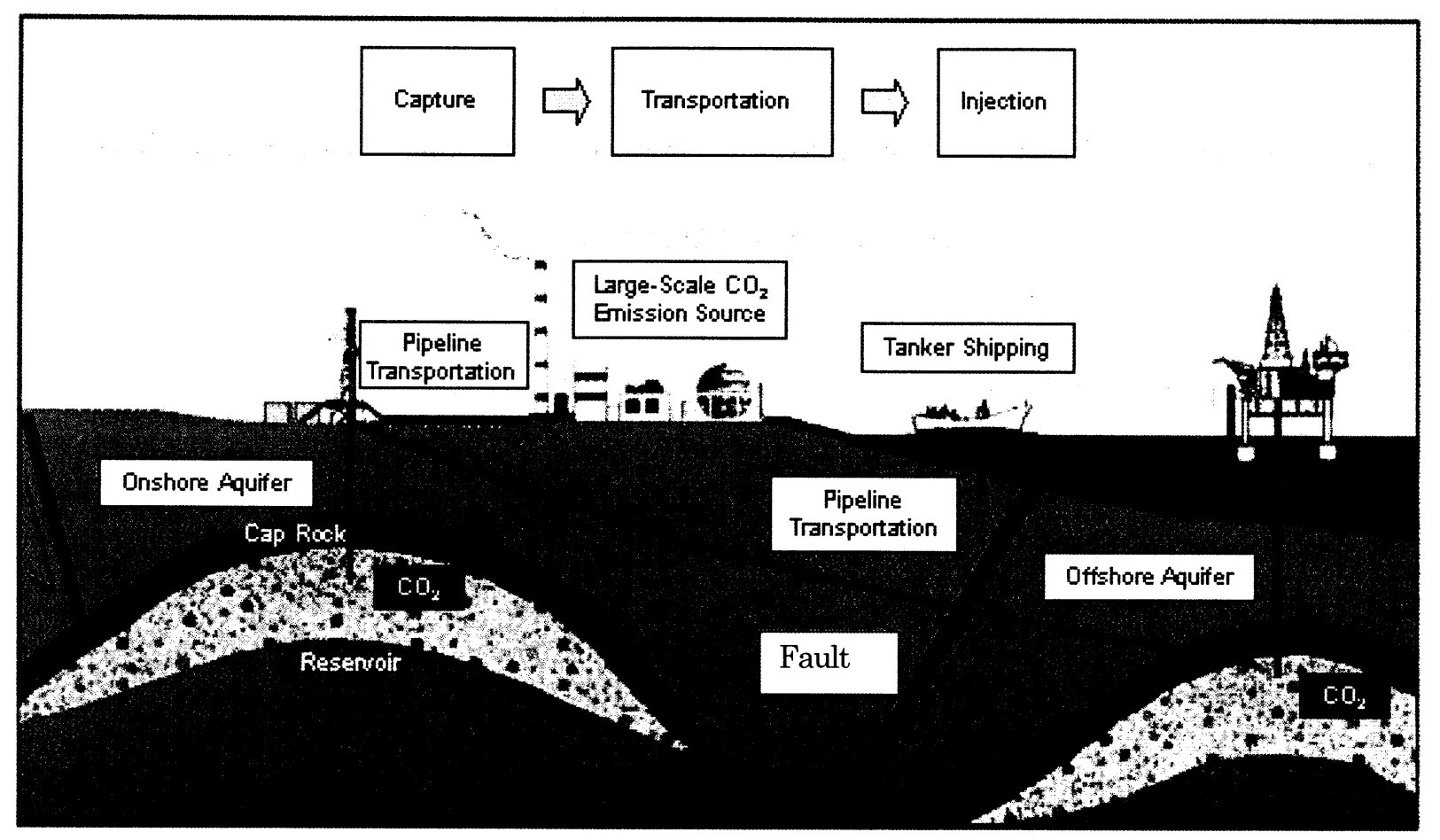

Fig. 1 A modified conceptual drawing of geological sequestration (Source: RITE)

cooperation with the Engineering Advancement Association of Japan (ENAA). ${ }^{10)}$

Although the study of $\mathrm{CO}_{2}$ geological sequestration has been extensively conducted in many research fields mainly including economic, chemical, multiphase flow, geological, and geomechnical aspects in recent years, few researchers touched on the mechanical changes of faults around the injection wells. ${ }^{9.10,12)}$ In our previous works, ${ }^{9,10)}$ possible fault parameters are evaluated in detail and fault stability assuciated with $\mathrm{CO}_{2}$ injection are also studied under consideration of the pore pressure. As a part of the $\mathrm{CO}_{2}$ geological research project cooperated with the RITE, in this study, the mechanical behavior of the fault around the injection well is focused to evaluate the influence of the sequestrated $\mathrm{CO}_{2}$ in the disposal aquifers. The research is conducted on parametric studies of possible properties of the disposal system, including $\mathrm{CO}_{2}$ plume sizes, injection well depths, injection pressures, and caprock permeabilities, which have not been thoroughly discussed in the previous studies.

In the present paper, at first, a geomechanical model is proposed for the finite element simulation. Then parametric studies, such as the thickness and spread width of $\mathrm{CO}_{2}$ plume, the injection pressure, the depth of injection well and the caprock permeability, are conducted to evaluate effects of the injection pressure and the buoyancy of $\mathrm{CO}_{2}$ plume on the mechanical changes of faults. Finally, the sensitivity of the shear stress change and relative slip displacement along the fault surface to the variation of the injection pressure, the thickness and spread width of $\mathrm{CO}_{2}$ plume is clearly interpreted. Although the geomechanical model of the fault is a little primitive, these constructive conclusions from current studies are useful to conduct to investigate the mechanical stability of the sequestration sites, especially near fault zones of seismic concerns.

\section{Model description}

\subsection{Geological simplification}

In our research, a conceptual sketch of geological system for $\mathrm{CO}_{2}$ sequestration in deep reservoirs is depicted in Fig. 1. This sketch is modified by adding two typical kinds of faults in a RITE conceptual drawing. By simplifying the complicated geological sequestration system into a representative plane strain model, Fig. 2 shows the two-dimensional (2-D) cross section of the present pilot model of a $\mathrm{CO}_{2}$ geological sequestration system. This sequestration system has four rock layer formations and the size is 2,000 meters laterally and 4,000 meters vertically. $\mathrm{A} \mathrm{CO}_{2}$ injection well over 1,200 meters deep is considered in the analysis. The injected $\mathrm{CO}_{2}$ plume has a thickness of $H$ and extended width of $X$. A normal fault with a dip angle of 45 degrees is 
embedded near the $\mathrm{CO}_{2}$ plume, the bottom end of which has a distance $W=250$ meters from the center of the $\mathrm{CO}_{2}$ plume. (See Fig. 2)

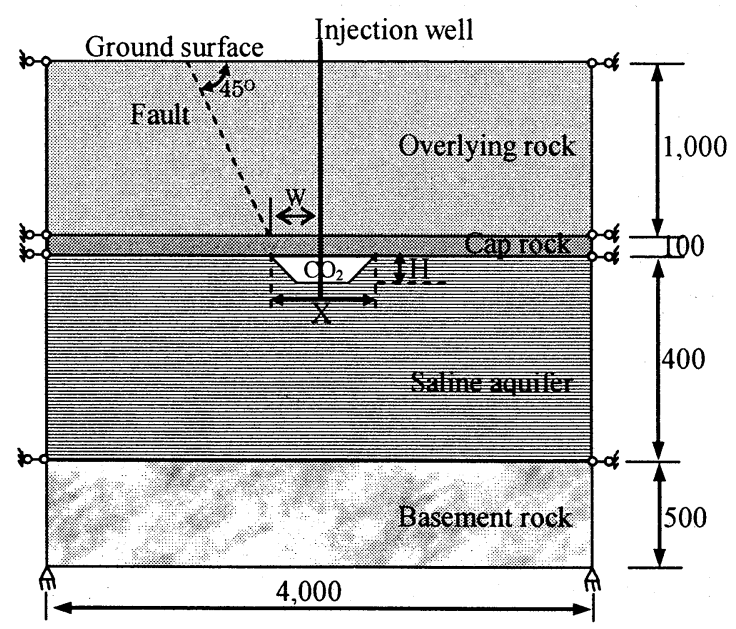

Fig. 2 Profile of the geomechanical model (Not to scale / unit: m)

\subsection{Fault contact model}

In the finite element analysis, modeling of the status development of the fault can be treated as a contact problem. In this present research, a classical spring model is adopted to consider the mechanical changes of the fault. Two flexible joint springs are used to devote to the simulation of the normal and tangential mechanical behavior of the fault. This proposed fault modeling can be depicted in the plot of Fig. 3. The same normal stiffness $2.0 \times 10^{7} \mathrm{~N} / \mathrm{m}$ and shear stiffness $1.0 \times 10^{7} \mathrm{~N} / \mathrm{m}$ of the fault surfaces are used in the analysis. This value choice of fault stiffness is based on the consideration of the common average values of faults in Kinki area, Japan. ${ }^{16)}$

\section{$2.3 \mathrm{CO}_{2}$ buoyancy supposition}

Due to the density difference between formation water and $\mathrm{CO}_{2}{ }^{1,14)}$, the supercritical $\mathrm{CO}_{2}$ will eventually float toward the bottom of the caprock layer. This density driven flow finally results in the birth of buoyancy of $\mathrm{CO}_{2}$ plume at the bottom of the confining caprock layer. In our research, the fault mechanical changes influenced by this buoyancy in the $\mathrm{CO}_{2}$-occupied zone will be evaluated. During the analysis, the buoyancy is applied around the injection well and along the bottom of the caprock layer as the distributed forces. This buoyancy pressure, $P_{\mathrm{CO}_{2}}$, at any point in the occupied zone is supposed to obey the following formula:

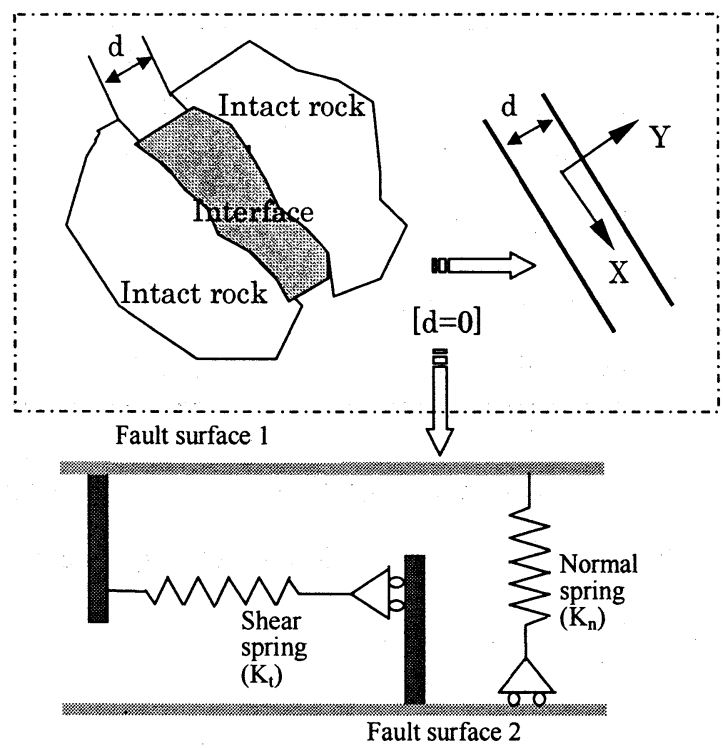

Fig. 3 Modeling and local coordinate for fault interfaces

$$
P_{c o_{2}}=g z \rho_{w}+g\left(\rho_{w}-\rho_{c o_{2}}\right) \xi
$$

where

$g \quad$ is the gravity acceleration,

$\rho_{w} \quad$ is the density of water,

$\rho_{\mathrm{Co}_{2}} \quad$ is the density of supercritical $\mathrm{CO}_{2}$,

$z \quad$ is the depth of the point from the earth surface,

$\xi \quad$ is the vertical distance from the lower edge of the $\mathrm{CO}_{2}$-occupied zone to that point.

\subsection{Injection pressure and its effect}

The injection pressure is very important to the initial stability of the geological sequestration system. ${ }^{13)}$ Although the injection pressure of Iwanohara Base pilot test reaches $7-11 \mathrm{MPa}$ at the top of the well and maximum $19 \mathrm{MPa}$ at the bottom of the well, we suppose that this injection pressure can be appropriate controlled under 20MPa. During the analysis, the injection pressure is applied by prescribing excess pore pressure at the end nodes around the injection well.

From another viewpoint, in order to consider the effect of the injection pressure on the strata, the response to an increase of the pore pressure within the whole storage aquifer (saline aquifer) is illustrated as shown in 
Table 1 Material properties

\begin{tabular}{llllll}
\hline Property & $\begin{array}{l}\text { Basement } \\
\text { rock }\end{array}$ & $\begin{array}{l}\text { Saline } \\
\text { aquifer }\end{array}$ & Caprock & $\begin{array}{l}\text { Overlying } \\
\text { rock }\end{array}$ & Fault \\
\hline Young's modulus $(\mathrm{Pa})$ & $1.0 \times 10^{10}$ & $2.0 \times 10^{9}$ & $2.0 \times 10^{9}$ & $1.0 \times 10^{9}$ & - \\
Poisson's ratio $(-)$ & 0.25 & 0.25 & 0.25 & 0.25 & - \\
Saturated density $\left(\mathrm{kg} / \mathrm{m}^{3}\right)$ & 2,600 & 1,900 & 1,900 & 1,900 & - \\
Permeability $(\mathrm{m} / \mathrm{s})$ & $1.0 \times 10^{-11}$ & $1.0 \times 10^{-6}$ & $1.0 \times 10^{-11}$ & $1.0 \times 10^{-7}$ & $1.0 \times 10^{-7}$ \\
\hline
\end{tabular}

Fig. 4. During the injection, the pore pressure distribution $\left(P_{f}\right)$ in the whole aquifer varies according to the following equations:

$$
\left\{\begin{array}{c}
P_{f}=0.01 z(1.0+0.2 x / 2000) \\
(900-H \leq z \leq 900,0 \leq x \leq 2000) \\
P_{f}=0.01 z(1.4-0.2 x / 2000) \\
(900-H \leq z \leq 900,2000 \leq x \leq 4000)
\end{array}\right.
$$

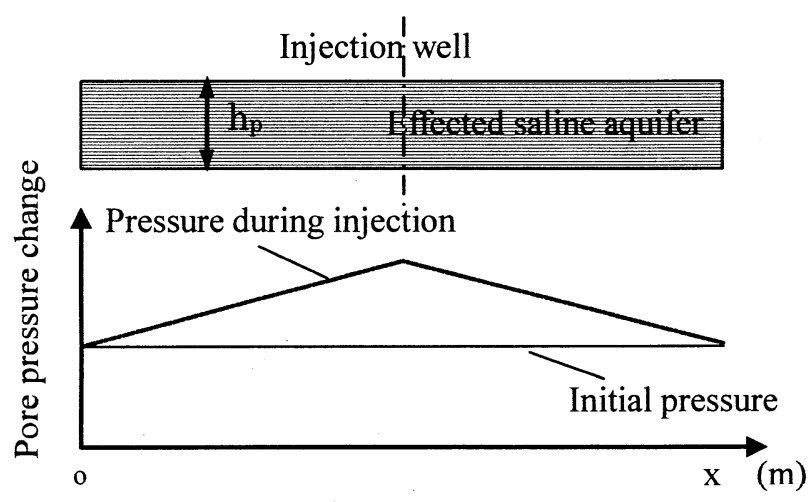

Fig. 4 Pore pressure distribution in the storage aquifer prior to and during the injection

\subsection{Constitutive model of fault interface ${ }^{2)}$}

On the fault surface, the elastic characters of normal component and tangent component can be described by giving the following stiffness matrix as follows,

$$
[\mathrm{K}]=\left[\begin{array}{cc}
-K_{t} & 0 \\
0 & -K_{n}
\end{array}\right]
$$

As for elastic behavior along the fault surface, the relationship between the force increment and the relative elastic displacement $\{\Delta(\Delta \mathrm{u})\}$ can be expressed as

$$
\{\Delta f\}=[K]\{\Delta(\Delta u)\}
$$

Finally, the stiffness formulation for a finite element can be constructed relating stress $\{\boldsymbol{\sigma}\}$ to $\operatorname{strain}\{\boldsymbol{\varepsilon}\}$, i.e.

$$
\{\boldsymbol{\sigma}\}=\mathbf{D}\{\boldsymbol{\varepsilon}\}
$$

where

$$
\begin{aligned}
& \{\boldsymbol{\sigma}\}=\left[\begin{array}{llllll}
\sigma_{x} & \sigma_{y} & \sigma_{z} & \tau_{x y} & \tau_{y z} & \tau_{z x}
\end{array}\right], \\
& \{\boldsymbol{\varepsilon}\}=\left[\begin{array}{llllll}
\varepsilon_{x} & \varepsilon_{y} & \varepsilon_{z} & \gamma_{x y} & \gamma_{y z} & \gamma_{z x}
\end{array}\right], \\
& \mathbf{D} \text { is a material stiffness matrix depends on the type of } \\
& \text { employed nonlinear solution algorithm. }
\end{aligned}
$$

\subsection{Rock material properties}

The material properties are given in Table 1 and correspond to a sandstone saline aquifer with a caprock layer of shale. In this analysis, the initial stress field is constructed in equilibrium with the initial weight of the materials.

\section{Results and discussion}

In this paper, the mechanical changes of faults around the injection well due to $\mathrm{CO}_{2}$ geological sequestration are focused to study. Herein, the main parametric, such as the thickness and width of $\mathrm{CO}_{2}$ plume, the injection pressure, the depth of injection well and the permeability of the caprock, will be studied to discuss the mechanical changes of faults. It should be mentioned that the injection pressure and the $\mathrm{CO}_{2}$ induced buoyancy will not be considered at the same time in current studies. The default value will be adopted in the model except for the special clear indication. They include $X=500$ meters, $H=100$ meters, injection well depth 1,200 meters. Case 29 through Case 32 are evaluated under the injection pressure, $19 \mathrm{MPa}$. 


\subsection{Influence of $\mathrm{CO}_{2}$ plume thickness}

In our research, at first, the shear stress change and the relative slip displacement along the fault surface have been examined under the consideration of different thickness of $\mathrm{CO}_{2}$ plume with the same spread width, $X=500$ meters. Table 2 lists four representative cases used to evaluate the influence of the thickness of $\mathrm{CO}_{2}$ plume. Effects of the injected $\mathrm{CO}_{2}$ volume, herein the thickness of $\mathrm{CO}_{2}$ plume, on the variation of shear stress along the fault surface are discussed in this section.

Table 2 Simulation cases for $\mathrm{CO}_{2}$ plume thickness

\begin{tabular}{cc}
\hline Case & $\mathrm{H}(\mathrm{m})$ \\
\hline Case 01 & 100 \\
Case 02 & 150 \\
Case 03 & 200 \\
Case 04 & 250 \\
\hline
\end{tabular}

Fig. 5 shows the variation of the shear stress change of the fault under the different disposal thickness, $H$ from 100 meters to 250 meters, of the $\mathrm{CO}_{2}$ plume. With the increase of the injection thickness of $\mathrm{CO}_{2}$ plume, the shear stress change accordingly increases but it is not smooth along the fault surfaces and behaves an abrupt change at the deep bottom end of the fault. This abrupt situation can be interpreted as the block effect of the caprock on the $\mathrm{CO}_{2}$ induced buoyancy transfer. It results in the small difference of mechanical changes at the bottom end of the fault. The gravity effect serves on an important role to bring local extrema around 700 meters. Relative slip displacements along the fault surfaces are plotted in Fig. 6. It is really significantly small under such supposed conditions of the geological sequestration system. The minus values of the shear stress change and the relative slip displacement denote that the upper slip trend of the fault.

\subsection{Influence of injection pressure}

Compressed $\mathrm{CO}_{2}$ is injected into the storage aquifer (sandstone) at a constant rate during the geological sequestration. As time goes on, the aquifer pressure will approach the lithostatic stress, so the suitable control of the injection pressure is very important during the sequestration process of $\mathrm{CO}_{2}$. In this study, four typical injection pressures at the bottom end of the injection well, see Table 3 , are adopted in order to consider the first geological sequestration project started at the Iwanohara Base of the Teikoku Oil Co. Ltd. in Nagaoka city, Niigata prefecture, Japan. It should be mentioned here that in this study we do not take into account the effects of time.

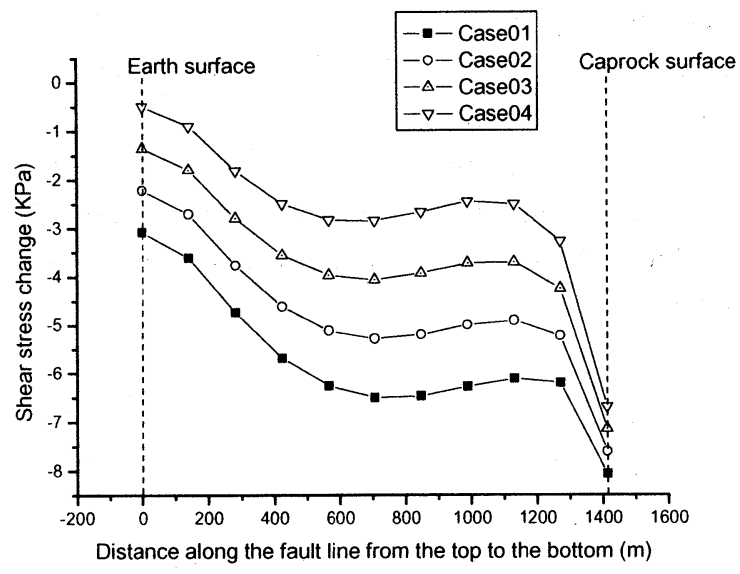

Fig. 5 Shear stress change of the fault under the different disposal thickness $(\mathrm{H})$ of $\mathrm{CO}_{2}$ plume

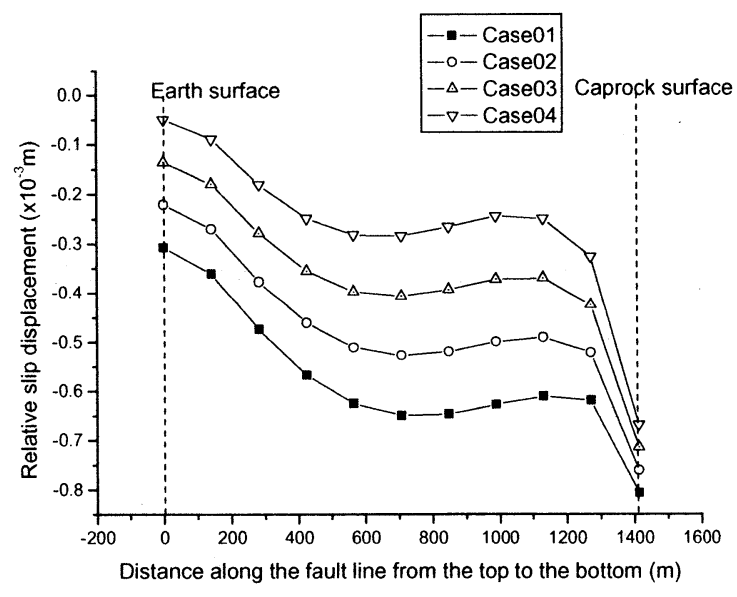

Fig. 6 Relative slip displacement of the fault surfaces under the different disposal thickness $(\mathrm{H})$ of $\mathrm{CO}_{2}$ plume

Table 3 Simulation cases for injection pressure

\begin{tabular}{cc}
\hline Case & Injection pressure (MPa) \\
\hline Case 05 & 7 \\
Case 06 & 11 \\
Case 07 & 19 \\
Case 08 & 25 \\
\hline
\end{tabular}


Fig. 7 presents the variation of the shear stress change of the whole fault surface under different injection pressures at the bottom end of the injection well. It shows that the shear stress change of the fault is seriously evident with the increase of the injection pressure. The injection pressure generates relative large slip displacement, shown in Fig. 8. The potential slip trend of the fault caused by the injection pressure is much more apparent than the one caused by the $\mathrm{CO}_{2}$ plume driven buoyancy. This apparent effect leads to local extrema generation in the deep part of the fault. That is why the injection pressures should be well controlled during the whole disposal process of the captured $\mathrm{CO}_{2}$ in order to avoid activating the tiptoe of the fault.

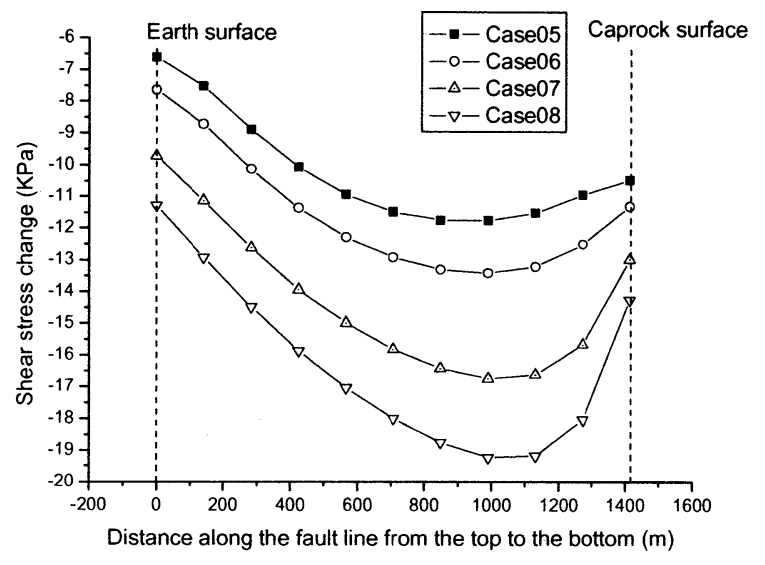

Fig. 7 Shear stress change of the fault under different well injection pressures

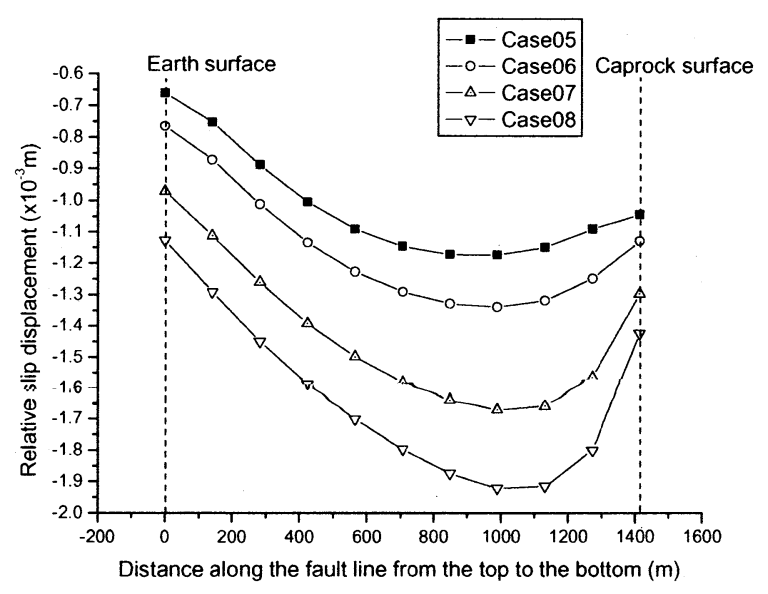

Fig. 8 Relative slip displacement of the fault surfaces under different well injection pressures

\subsection{Influence of injection depth}

In general, the captured $\mathrm{CO}_{2}$ is injected into over 800 meters deep aquifers. In this study, the captured and processed $\mathrm{CO}_{2}$ is injected into 1,200 meters deep saline aquifers and the injected $\mathrm{CO}_{2}$ is supercritical under such a depth level. In our simulations, the influence of different depths of the injection well is considered to evaluate the mechanical changes of the fault via four cases. Table 4 gives such four cases used in this section. Fig. 9 presents the variation of the shear stress change of the fault under the injection well depth, hw, from 1,100 meters to 1,400 meters at the same injection pressure, $19 \mathrm{MPa}$, at the bottom of the well. Fig. 10 depicts the relative slip displacement of the fault surfaces of these four cases. Although the injection depth increased 300 meters from 1,100 meters, the variation of the shear stress change is not so significant among these four cases. One of the reasons is that transferred effective pore pressure to the fault nearly the same under such conditions. Case 09 behaves a relative obvious difference rather than other three cases in Fig. 9 and Fig. 10. Its injection point just lies at the bottom surface of the caprock layer. It should be noted that it seems difficult to understand why the shallow injection depth results in relative larger mechanical changes in these four cases. It is reasonable that because the effected thickness of the saline aquifer, $h_{p}$, see in Fig. 4, is thicker to the deep injection case, e.g. Case12. It leads to larger pore pressure change in the storage aquifer according to the equation (2). This result may be interpreted that the injection pressure has a close relationship with the injection well depth. It sounds reasonable that some researchers pointed out that the depth of 800 meters is an acceptable depth in most practical disposal projects. ${ }^{5}$. 13)

Table 4 Simulation cases for injection depth

\begin{tabular}{cc}
\hline Case & Injection well depth, hw $(\mathrm{m})$ \\
\hline Case 09 & 1,100 \\
Case 10 & 1,200 \\
Case 11 & 1,300 \\
Case 12 & 1,400 \\
\hline
\end{tabular}

\subsection{Influence of spread width of $\mathrm{CO}_{2}$ plume}

In the above study, we discussed the influence of the injection thickness of $\mathrm{CO}_{2}$ plume. Herein sixteen cases listed in Table 5 will be studied according to the different spread width $(X)$ of $\mathrm{CO}_{2}$ plume, from 500 meters to 800 meters (see Fig. 2), at the same time 
considering the injection thickness $(H)$ increasing from 100 meters to 250 meters.

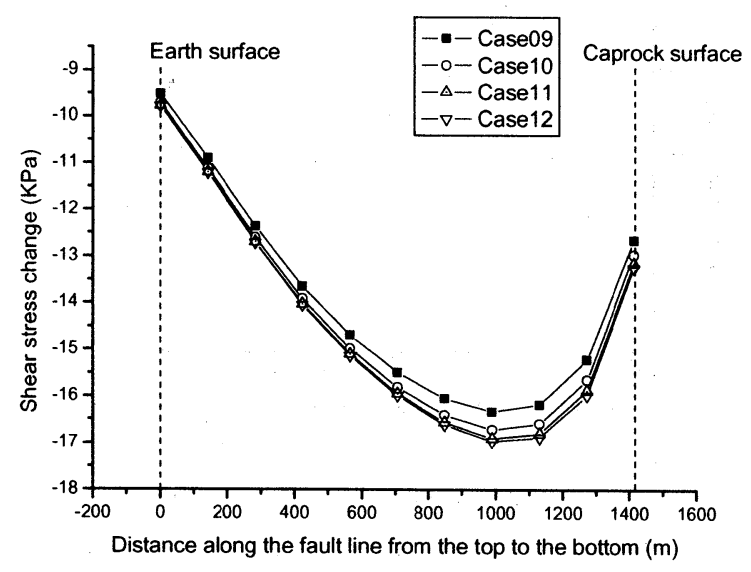

Fig. 9 Shear stress change of the fault under the different disposal depth (hw) of injection well

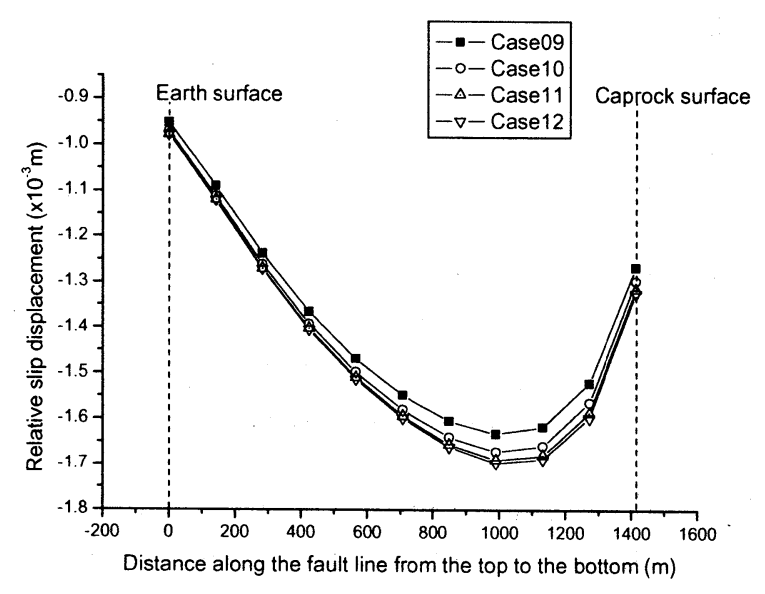

Fig. 10 Relative slip displacement of the fault surfaces under the different disposal depth (hw) of injection well

Fig. 11 presents the variation of the shear stress change of the fault under the increase of spread width $(X)$ and the same disposal thickness $(H=100 \mathrm{~m})$ of $\mathrm{CO}_{2}$ plume. It shows that the horizontal spread of $\mathrm{CO}_{2}$ plume along the bottom of the confining caprock layer increases the shear stress change along the whole fault surface, but obviously the $\mathrm{CO}_{2}$ plume driven buoyancy has weak influence on the shallow part of the fault. The relative slip displacement shows in Fig. 12. It is still small under such a case. It seems that the effects of the buoyancy induced by $\mathrm{CO}_{2}$ plume are centralizing to apply the close surroundings of the injection well. The same trend can be further understood from Fig. 13 through Fig. 18 according to different disposal thickness of $\mathrm{CO}_{2}$ plume. With the enlargement of the whole volume of $\mathrm{CO}_{2}$ plume, both the thickness $(H)$ and the spread width $(X)$, the even variation of the shear stress change is obtained from Fig. 11 to Fig. 18. It also can be obtained that the shear stress change and the relative slip displacement of the fault has a significant increase when the spread width of $\mathrm{CO}_{2}$ plume exceeds the tiptoe of the fault, i.e. $X>500 \mathrm{~m}$.

Table 5 Simulation cases for spread width of plume

\begin{tabular}{|c|c|c|}
\hline Case & $H(m)$ & $X(m)$ \\
\hline Case 13 & 100 & 500 \\
\hline Case 14 & 100 & 600 \\
\hline Case 15 & 100 & 700 \\
\hline Case 16 & 100 & 800 \\
\hline Case 17 & 150 & 500 \\
\hline Case 18 & 150 & 600 \\
\hline Case 19 & 150 & 700 \\
\hline Case 20 & 150 & 800 \\
\hline Case 21 & 200 & 500 \\
\hline Case 22 & 200 & 600 \\
\hline Case 23 & 200 & 700 \\
\hline Case 24 & 200 & 800 \\
\hline Case 25 & 250 & 500 \\
\hline Case 26 & 250 & 600 \\
\hline Case 27 & 250 & 700 \\
\hline Case 28 & 250 & 800 \\
\hline
\end{tabular}

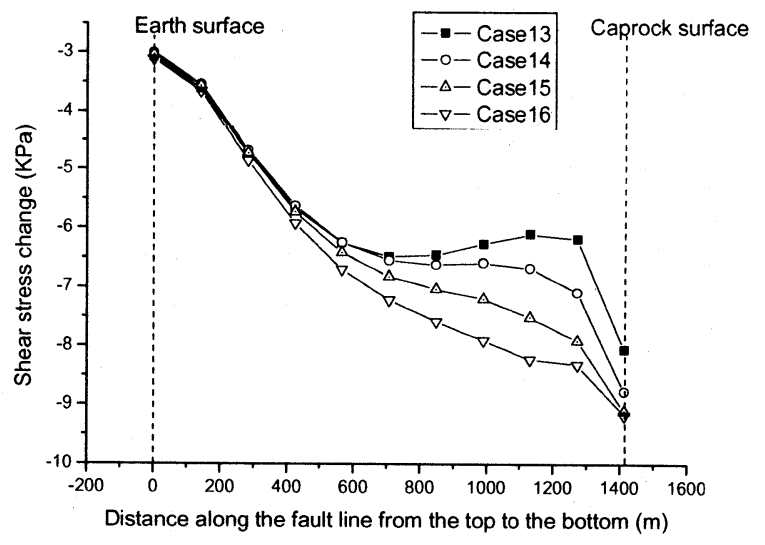

Fig. 11 Shear stress change of the fault under the different spread width $(X)$ and the same disposal thickness $(H=100 \mathrm{~m})$ of $\mathrm{CO}_{2}$ plume 


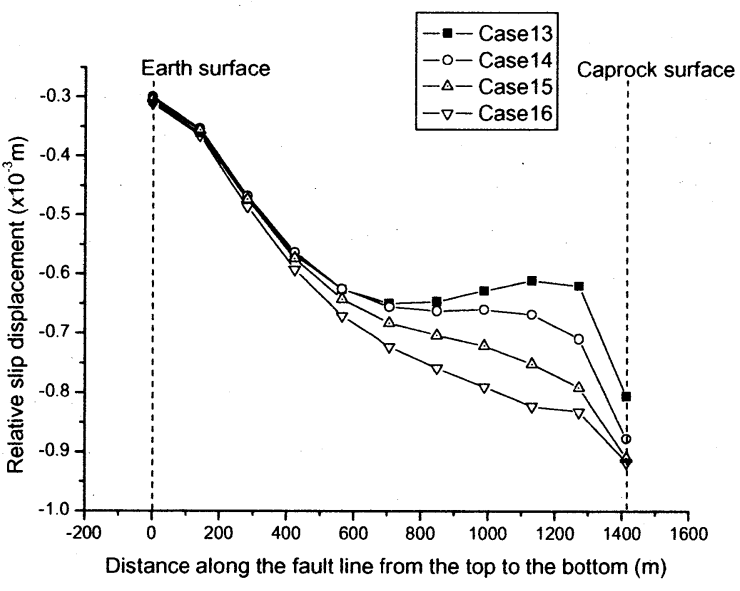

Fig. 12 Relative slip displacement of the fault surfaces under the different spread width $(X)$ and the same disposal thickness $(\mathrm{H}=100 \mathrm{~m})$ of $\mathrm{CO}_{2}$ plume

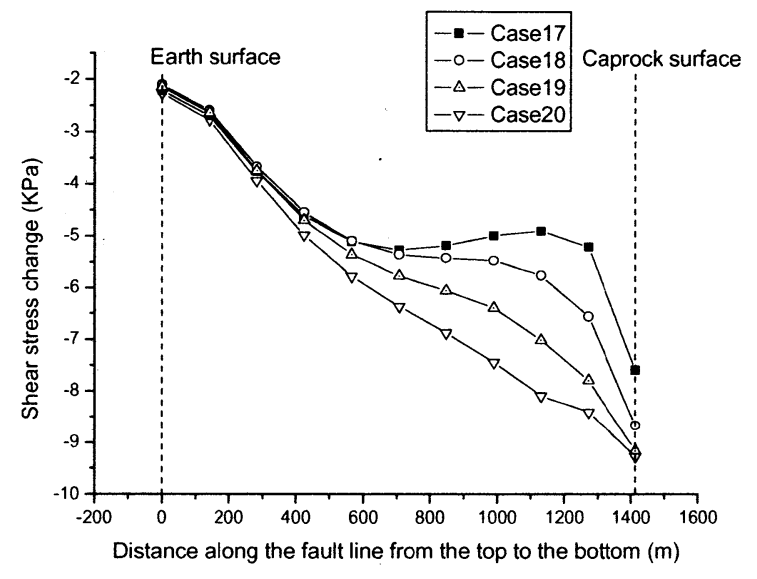

Fig. 13 Shear stress change of the fault under the different spread width $(X)$ and the same disposal thickness $(H=150 \mathrm{~m})$ of $\mathrm{CO}_{2}$ plume

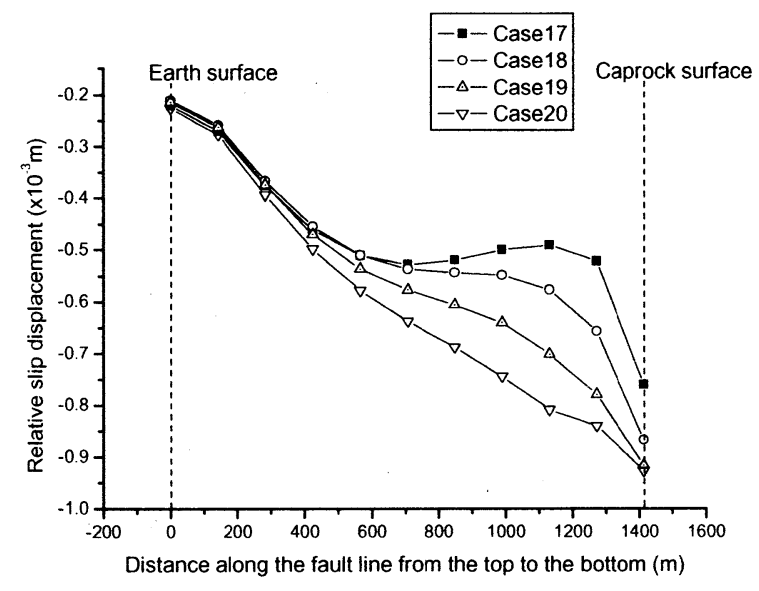

Fig. 14 Relative slip displacement of the fault surfaces under the different spread width $(X)$ and the same disposal thickness $(\mathrm{H}=150 \mathrm{~m})$ of $\mathrm{CO}_{2}$ plume

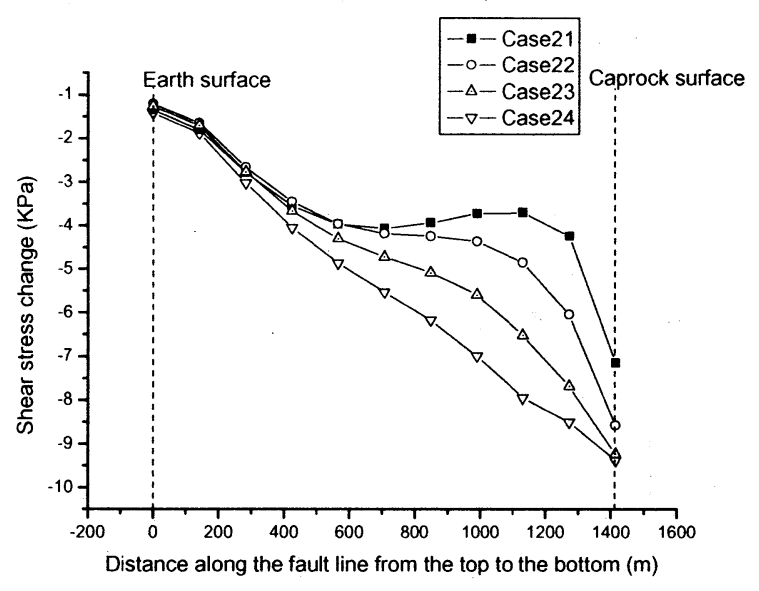

Fig. 15 Shear stress change of the fault under the different spread width $(X)$ and the same disposal thickness $(\mathrm{H}=200 \mathrm{~m})$ of $\mathrm{CO}_{2}$ plume

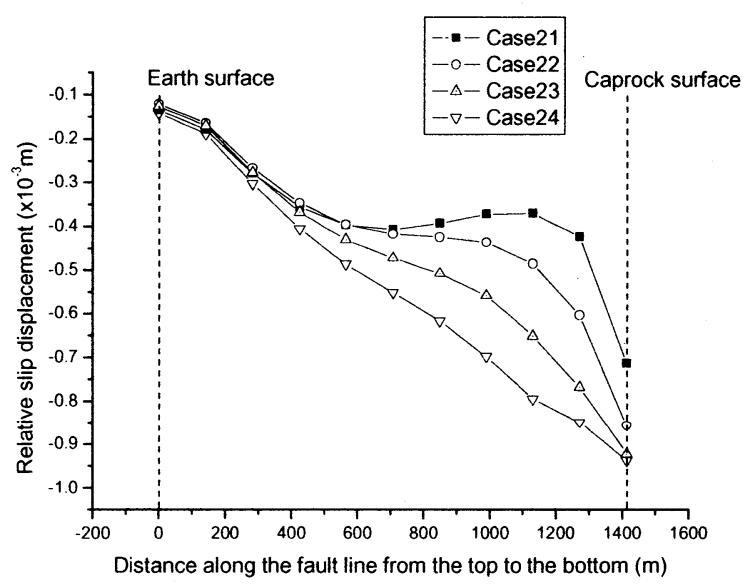

Fig.16 Relative slip displacement of the fault surfaces under the different spread width $(X)$ and the same disposal thickness $(H=200 \mathrm{~m})$ of $\mathrm{CO}_{2}$ plume

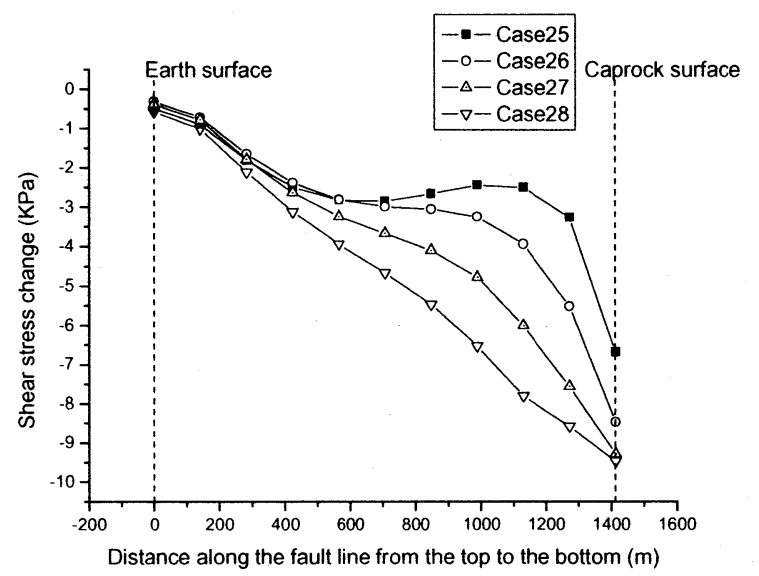

Fig. 17 Shear stress change of the fault under the different spread width $(X)$ and the same disposal thickness $(H=250 \mathrm{~m})$ of $\mathrm{CO}_{2}$ plume 


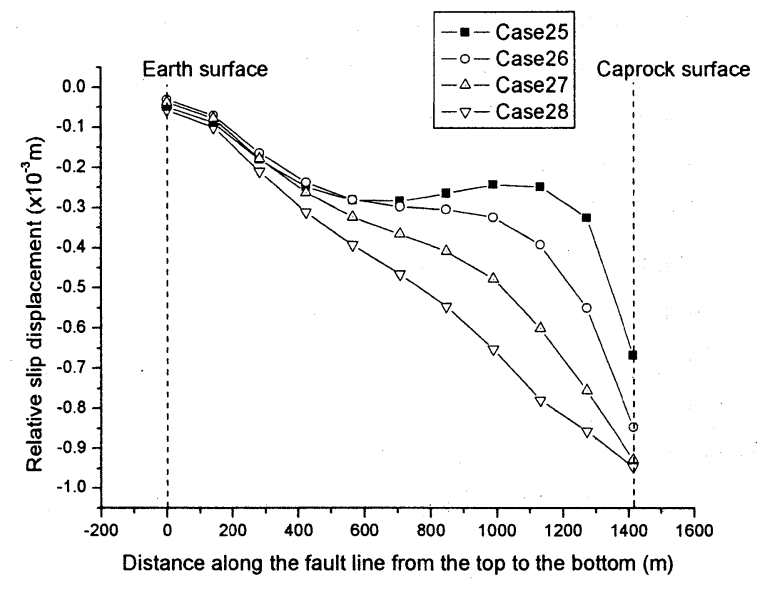

Fig. 18 Relative slip displacement of the fault surfaces under the different spread width $(X)$ and the same disposal thickness $(\mathrm{H}=250 \mathrm{~m})$ of $\mathrm{CO}_{2}$ plume

\subsection{Influence of caprock permeability}

In this study, the caprock of shale formations is proposed. Four cases are given in Table 6 with considering different values of the shale permeability. Fig. 19 presents the variation of the shear stress change of the fault with the same injection pressure of $19 \mathrm{MPa}$. It shows the variation of the shear stress change between Case 29 and 30, Case 31 and 32, along the fault surface is nearly the same. A main reason is because the chosen values of these cases fall into the range of the permeability of compact formations in our analysis. Fig. 20 shows the relative slip displacement. It is a little confused that why lower permeability results in the relative obvious slip displacement change under such four cases. It may be interpreted that the caprock with the low permeability serves as an important role on the elastic stress transfer of the injection pressure. It also should be mentioned that the intricate results shown in Fig. 19 and Fig. 20 under such specific cases in this section seriously depend on the selection of the permeability value of the caprock layer and the overlying rock layer including the fault.

Table 6 Simulation cases for the caprock permeability

\begin{tabular}{cc}
\hline Case & Permeability $(\mathrm{m} / \mathrm{s})$ \\
\hline Case 29 & $1.0 \times 10^{-11}$ \\
Case 30 & $1.0 \times 10^{-13}$ \\
Case 31 & $1.0 \times 10^{-15}$ \\
Case 32 & $1.0 \times 10^{-17}$ \\
\hline
\end{tabular}

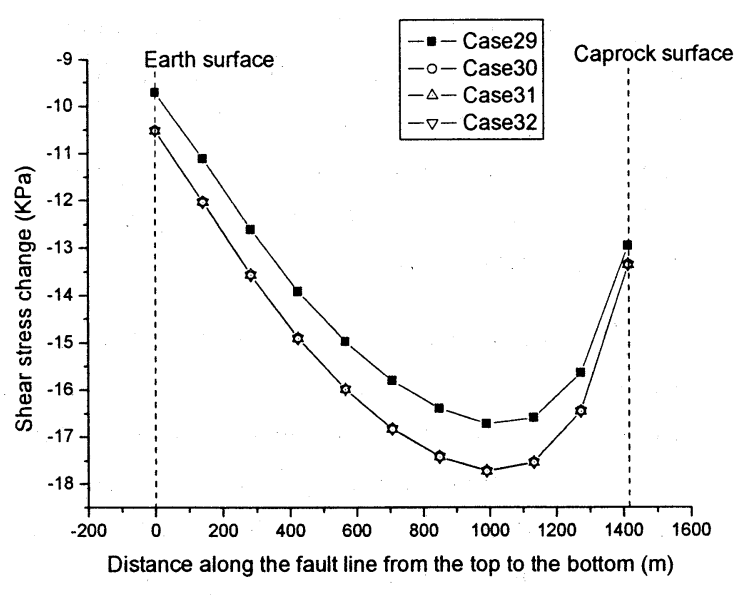

Fig. 19 Shear stress change of the fault under different values of the caprock permeability

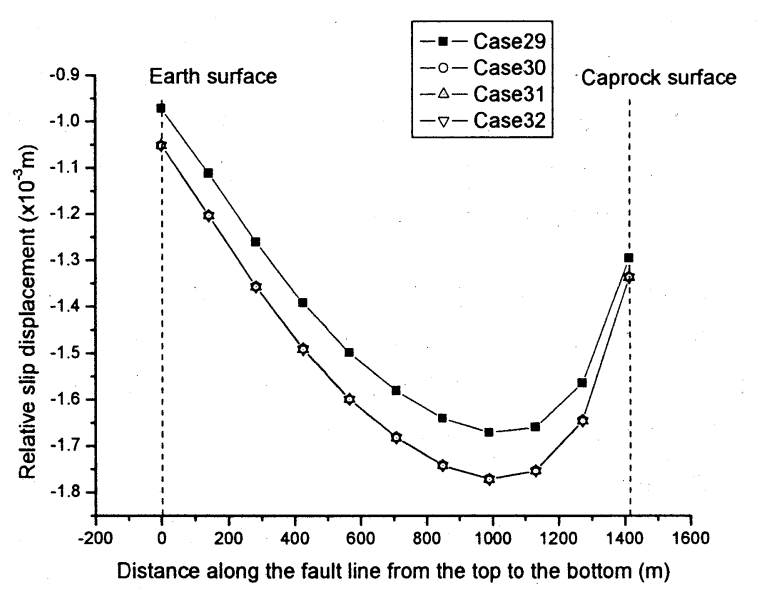

Fig. 20 Relative slip displacement of the fault surfaces under different values of the caprock permeability

\section{Conclusive remark and future work}

From the case studies discussed above, the following constructive conclusions are suggested:

(1) With the increase of the injection thickness of $\mathrm{CO}_{2}$ plume, the shear stress change and the relative slip displacement of the fault accordingly increases and behaves an abrupt change at the deep bottom end of the fault.

(2) The shear stress change and the relative slip displacement of the fault is evident with the increase of the injection pressure. The potential slip trend of the fault caused by the injection pressure is much more apparent than the one caused by the $\mathrm{CO}_{2}$ plume driven buoyancy. The injection pressures should be well controlled during the whole geological sequestration process. 
(3) The variation of the shear stress change and the relative slip displacement are not evident when increasing the injection depth from 1,100 meters from 1,400 meters in our study. An acceptable and cost-effective injection depth may be proposed with close considerations of the injection pressure for a practical disposal project.

(4) The horizontal spread of $\mathrm{CO}_{2}$ plume along the bottom of the caprock layer fast increases the shear stress change along the whole fault surface, but the $\mathrm{CO}_{2}$ plume driven buoyancy has weak influence on the shallow part of the fault. With the enlargement of the whole volume of $\mathrm{CO}_{2}$ plume, both the thickness and the spread width, the even variation of the shear stress change is approached.

(5) The variation of the shear stress change along the fault surface is influenced under the decrease of the caprock permeability, but the effects on the shear stress change and the relative slip displacement close depend on the selection of the permeability value of the caprock layer and the overlying rock layer including the fault.

Finally, it is important to state that most of the process of the geological $\mathrm{CO}_{2}$ sequestration is site specific, so further studies are urgently needed on cases certainties and field monitoring.

In the future study, a multi-purpose integrated thermo-hydro-mechanical simulator will be constructed to do evaluations of the potential hydraulic fracturing of the caprock formation and fault reaction. On the other hand, the multiphase characteristics of $\mathrm{CO}_{2}$ disposal systems should be involved in our numerical analysis.

\section{Acknowledgements}

This work is firstly supported by Research Institute of Innovative Technology for the Earth (RITE), Japan. The authors gratefully acknowledge the support by the $\mathrm{CO}_{2}$ Sequestration Research Group of RITE. The authors would also like to thank three anonymous reviewers for their many helpful suggestions and comments.

\section{References}

1) Garcia, J. E., Density of aqueous solutions of $\mathrm{CO}_{2}$, Lawrence Berkeley National Laboratory, Paper LBNL-49023, October 10, 2001

2) Gunter, W. D., Bachu, S., Law, D. H. -S., Marwaha, V., Drysdale, D. L., MacDonald, D. E., McCann, T.
J., Technical and economic feasibility of $\mathrm{CO}_{2}$ disposal in aquifers within the Alberta sedimentary basin, Canada, Energy Conversion and Management, 37, pp.1135-1142, 1996

3) HKS Inc., ABAQUS Theory Manual 6.2, Pawtucket, USA, 2001

4) Herzog, H., Caldeira, K. and Adams, E., Encyclopedia of Ocean Sciences, Chapter Carbon Sequestration via Direct Injection, Academic Press, London, UK, 2001

5) Hitchon, B., Aquifer Disposal of Carbon Dioxide, Geoscience Publishing Ltd., Sherwood Park, Canada, 1996

6) Holt, T., Jensen, J. I., Lindeberg, E., Underground storage of $\mathrm{CO}_{2}$ in aquifers and oil reservoirs, Energy Conversion and Management, 36, pp.535-538, 1995

7) Kaya, Y., Koide, H., Nakaya, S., Ohsumi, T., Takita, K., Yoshimura, H., Underground sequestration of carbon dioxide in tectonically active area, in $D$. Williams, B. Durie, P. McMullan, C. Paulson, and A. Smith, Eds., Greenhouse Gas Control Technologies (GHGT-5), CSIRO Publishing, (2001), pp. 296-298, 2000

8) Koide, H., Shindo, Y., Tazaki, Y., Iijima, M., Ito., K., Kimura, N. and Omata, K., Deep sub-seabed disposal of $\mathrm{CO}_{2}$ - the most protective storage, Energy Conversion and Management, 38, pp. 253-258, 1997

9) Li, Q., Wu, Z. S., Li, X. C., Ohsumi, T. and Koide, H., Numerical simulation on faults activities induced by the injection of $\mathrm{CO}_{2}$ in deep saline aquifers, XXIII General Assembly of the International Union of Geodesy and Geophysics (IUGG2003), Sapporo, Japan, A489, June 30-July 11, 2003

10)Li, Q., Wu, Z. S. and Li, X. C., Stability evaluation of fault activity induced by $\mathrm{CO}_{2}$ injection into deep saline aquifers, Journal of Applied Mechanics, JSCE, 7, pp.883-890, August 2004

11)Mitsukawa, H., Global warming prevention technologies in Japan, in J. Gale and Y. Kaya Eds., Greenhouse Gas Control Technologies (GHGT-6), Pergamon Publishing, pp.5-10, 2002

12)Orlic, B. and van Eijs, R., Modelling of deep subsurface for geohazard risk assessment, Finite Elements in Civil Engineering Applications, Proceedings of the Third DIANA World Conference, Tokyo, Japan, 9-11 October, pp.343-351, 2002

13)Rutqvist, J. and Tsang, C. -F., A study of caprock hydromechanical changes associated with $\mathrm{CO}_{2}$-injection into a brine formation, Environmental Geology, 42, pp. 296-305, 2002

14)Song, Y., Chen, B., Nishio, M. and Akai, M, Density change of underground water due to $\mathrm{CO}_{2}$ dissolution, 
Greenhouse Gas Control Technologies (GHGT-7), in press

15)Wong, S., MacLeod, K., Gunter, W. D., Mavor, M. J, and Gale, J., $\mathrm{CO}_{2}$-enhanced coalbed methane recovery demonstration pilot - a case for Australia. Proceedings of the 2001 International Coalbed
Methane Symposium, Tuscaloosa, Alabama, USA, pp. 75-86, May 14-18, 2001

16)平成 11 年度,「低レベル放射性廃棄物処分可視画像 化調査報告書 （平成 3 11 年度検討の総括）」，財 団法人 原子力環境整備センター，平成 12 年 3 月

(Received April 15, 2005) 